\title{
Integrating Computational Modeling Modules into Undergraduate Materials Science and Engineering Education
}

\section{Dr. Lan (Samantha) Li, Boise State University}

Dr. Lan (Samantha) Li is an assistant professor at the Department of Materials Science and Engineering (MSE), Boise State University in Idaho. She has expertise in computational modeling techniques. She teaches undergraduate and graduate students different computational modeling methods, such as density functional theory, phase field, and finite element, and outreaches to K-12 kids to promote the field and STEM education. Dr. Li assists the MSE department in integrating computational modeling training into MSE undergraduate core curriculum. She presently serves as a chair of TMS (The Minerals, Metals \& Materials Society) Education Committee. Address: Department of Materials Science and Engineering, Boise State University, 1910 University Drive, Boise, ID 83725-2090; Phone: (208) 426-5669; Email: lanli@boisestate.edu 


\title{
Integrating Computational Modeling Modules into Undergraduate Materials Science and Engineering Education
}

\begin{abstract}
To meet national workforce need, we integrated computational modeling training into undergraduate materials science and engineering (MSE) courses, including Thermodynamics, and Structure of Materials. We also flipped the courses, requiring students to self-study topics outside the class. In the class, the instructors focused on demonstrating real-world materials problems and guiding the students to solve the problems using different computational modeling techniques. Learning the computational modeling concepts within a short period of time was challenging to the students. Another challenge was that the students had various STEM backgrounds, such as MSE, mechanical engineering, and physics. In order to foster student learning, engage student interest and seamlessly couple computational modeling modules with the courses, real-world problems, examples and homework were all developed based on student background and interest. For each lecture, $90 \%$ of the time was arranged for quiz, problem solving, and hands-on training. The students could improve their understanding of computational modeling concepts through practice. This paper presents the above teaching strategies and demonstrates one computational module used for teaching the students how to estimate point defect formation energy with a computational modeling tool. The student feedback suggests that integrating computational modeling training into undergraduate curriculum is feasible. However, it posts some challenges, such as teaching hours and teaching balance between computational modeling theory and practice, for the students and instructor. The paper also discusses the improvement plan.
\end{abstract}




\section{Introduction}

Computation will be a fundamental skill used by everyone in the world by the middle of the 21 st Century ${ }^{1}$. It requires more than programming using a computer but also thinking at multiple levels of abstraction. Advances in computation allow researchers and engineers across all disciplines to envision new problem-solving strategies and to test new solutions in both the virtual and real world ${ }^{2}$. In the past decade, computation has made possible profound leaps of innovation and imagination as it facilitates our efforts to predict problems and develop strategies to solve the problems before they appear, and advances our understanding of natural phenomena surrounding us. These advances drive the need for educated individuals who can bring the power of computing to solve the problems in a fast and effective way.

The growing impact of computation in materials research is clear ${ }^{3}$. In its report on Integrated Computational Materials Engineering (ICME), the National Research Council of the National Academies of Sciences states, "Integrating materials, computational tools and information with sophisticated computational and analytical tools already in use in engineering fields... [promises] to shorten the materials development cycle from its current 10-20 years to 2 or 3 years", In addition, at least one out of five research articles included a word 'computational' or 'simulation' in the key word (including the title and the abstract) ${ }^{5}$. Recognizing the growing role of computational modeling in materials research has led to a substantial expansion in the number of computational materials science faculty members in universities across the US. The growing number of faculties has become a sizeable increase in the rate at which undergraduate and graduate students are being trained in the field. In recent years, many universities have begun integrating computational materials science into their curriculum to introduce various computational modeling methods and tools ${ }^{6}$. The required computational modeling methods are abstract and difficult for students to understand, because conceptual understanding of those methods require multidisciplinary backgrounds, such as fundamental physics, chemistry, mathematics, materials science, computer science etc. As a result, students are not fully achieving desired learning outcomes-while they may learn to solve problems within an individual computational materials science course, they often appear to lack a robust conceptual understanding of computational modeling methods that is a must for real-world application. Such learning difficulty causes students to lose interest in the field and reduce their willingness to use the computational modeling methods in future research and career.

Increasing student's awareness of the important role of computational modeling in academia, national lab and industry as well as fostering student learning in the field are two key activities in teaching. As a prototype, we integrated computational modeling training into two undergraduate materials science courses, including Structure of Materials course and Thermodynamics course. We had four computational modeling classes in each course. The students were required to finish a reading assignment for computational modeling concepts before each class. $90 \%$ of the class time was arranged for quiz to assess students' understanding of computational modeling concepts, contemporary materials problem solving, and hands-on practice. The teaching activities were coupled to the course topics, demonstrating to the students how to use different computational methods and tools to visualize and study materials problems. 
This paper discusses the above teaching strategies and demonstrates one computational modeling module. Student feedback on the modules is presented. Feedback analysis and improvement plan are also discussed.

\section{Computational Modeling Module Development}

The computational modeling modules were developed by materials science and engineering (MSE) faculty and implemented in two MSE undergraduate core courses (Structure of Materials course and Thermodynamics course) and offered to junior students in the fall semester. The module development was guided by three main principles:

- Simplify computational modeling concepts and explain them by presenting real-world examples in a language familiar to the students.

Computational modeling encompasses a diverse set of scientific and engineering subjects and skills, ranging from algorithms and data structures to analysis, visualization and presentation. It is impossible for the students to learn all the required subjects and skills before the training. Therefore, two crucial issues need to be addressed. One is how many and deep concepts are covered in the training. Second is what real-world examples can be used to explain the concepts.

- Teach in a problem-driven way

This includes presenting only the problems relevant to course content. For example, in the Thermodynamics course, an in-class activity was to determine the equilibrium state of a material by solving the Helmholtz free energy equation using a phase field modeling method. In the Structure of Materials course, density functional theory simulation method was used to estimate bond lengths and strengths. This, in turn, motivates the students to explore the modeling procedure, and the applications and limitations of the modeling methods.

- Assess student learning over the semester.

The goals are to increase student engagement and make the computational modeling modules fit better to students' knowledge levels. To fulfill the goals, in-class quizzes, homework, and a term project were all performed over the semester. The module topics were changed based on the feedback of those activates.

\section{Computational Modeling Module Implementation}

\section{Module Overview}

Each course included four computational modeling classes. According to the course content, different computational modeling techniques were taught. The techniques could be classified into density functional theory and phase field modeling methods. The students finished a reading assignment for computational modeling concepts before each class. The class was arranged for quiz to assess students' understanding of computational modeling concepts, contemporary materials problem solving, and hands-on training. The computational modeling modules must seamlessly couple with the course contents, demonstrate real-world problems, and improve students' understanding of computational modeling and materials concepts. They included: 
Structure of Materials Course

- Introduction to Computational Modeling

- Atom and Bonding Simulations

- Point Defect Formation Energy Calculations

- Defect Diffusion Simulations

\section{Thermodynamics Course}

- Energy of Reactions

- Equilibrium Simulations

- G vs. x Curves

- Phase Separation Simulations

The above eight modules taught the students two computational modeling methods: firstprinciples simulation method and phase field modeling method. The first-principles method is based on density functional theory (i.e. quantum mechanics) and used to predict structural stability, atomic bonding nature, and different material properties. The phase field method is thermodynamics-based to model phase changes and evolving microstructures in materials. With no doubt, an ability to use these two modeling methods in the materials design and development can provide insight into atomic structure, predict materials phase, stability and properties, which align well to ICME goals ${ }^{4}$.

\section{Module Materials and Implementation}

Each module included pre-, in- and post-class documents and activities, designed with the three column lecture planning table. Table I was applied to the point defect formation energy calculation module taught in the Structure of Materials course.

Students were required to study the basic modeling concepts before the class. The first 15 minutes of the class were for a quiz, followed by quiz solution analysis and explanation. This inclass quiz assessed students' understanding of the modeling concepts they self-studied before the class. The instructor also answered students' questions. The rest of the time in the class was for hands-on practice. The in-class exercises were designed for different course topics and learning outcomes. For example, the course topic was point defects, including interstitial atom and vacancy. In the real world, the presence of point defects would change materials structures, properties and performance. Predicting the effect of the point defects is crucial for materials development. In the class, the instructor demonstrated how to simulate point defects in graphene. The presence of the point defects in graphene is the consequence of irradiation damage. The defects can affect the structural stability of the graphene. Therefore, the students learned how to create a computational modeling input file to determine the stable configuration of a point defect in graphene, and how to calculate the formation energy of the point defect using the computational modeling tool. During the hands-on practice, the students worked within the teams to discuss the results and help each other setup the computational models. In order to assess the intended learning outcomes, the instructor provided a take-home computational modeling exam to the students besides an assignment for each class. Both homework and exams 
included conceptual and computational modeling questions. The students were also required to use the computational modeling techniques in their term projects.

Table I Three column lecture planning table used for point defect formation energy calculation module development

\begin{tabular}{|c|c|c|c|}
\hline Learning Outcome & Pre-Class Activities & In-Class Activities & $\begin{array}{c}\text { Post-Class Activities, } \\
\text { e.g. Assessment and } \\
\text { Feedback }\end{array}$ \\
\hline $\begin{array}{l}\text { 1. Understand point } \\
\text { defects, including } \\
\text { adatom, vacancy, Stone- } \\
\text { Wales defect in carbon- } \\
\text { based materials. }\end{array}$ & $\begin{array}{l}\text { Read Li et al. "Defect } \\
\text { energies of graphite } \\
\text { Density-functional } \\
\text { calculations", Phys. Rev. } \\
\text { B 72, } 184109(2005)\end{array}$ & $\begin{array}{l}\text { 5-min quiz and solutions, } \\
\text { Q+A session }\end{array}$ & $\begin{array}{l}\text { Conceptual questions in } \\
\text { assignment }\end{array}$ \\
\hline $\begin{array}{l}\text { 2. Prepare your own } \\
\text { computational modeling } \\
\text { input file. }\end{array}$ & $\begin{array}{l}\text { Payne } \text { et al. "Iterative } \\
\text { minimization techniques } \\
\text { for ab initio total-energy } \\
\text { calculations: molecular } \\
\text { dynamics and conjugate } \\
\text { gradients", Rev. Mod. } \\
\text { Phys } 64,1045 \text { (1992) } \\
\& \\
\text { "Must-remember-note" } \\
\text { for quantum mechanical } \\
\text { simulation, summarized } \\
\text { by the instructor. }\end{array}$ & $\begin{array}{l}\text { Create a computational } \\
\text { modeling input file to } \\
\text { determine the stable } \\
\text { configuration of a point } \\
\text { defect in graphene } \\
\text { material. }\end{array}$ & $\begin{array}{l}\text { Computational modeling } \\
\text { questions in assignment, } \\
\text { take-home computational } \\
\text { modeling exam, and } \\
\text { individual term project }\end{array}$ \\
\hline $\begin{array}{l}\text { 3. Apply the modeling } \\
\text { methods to determine } \\
\text { point defect stability in } \\
\text { the materials. }\end{array}$ & $\begin{array}{l}\text { Read Li et al. "Defect } \\
\text { energies of graphite } \\
\text { Density-functional } \\
\text { calculations", Phys. Rev. } \\
\text { B 72, } 184109(2005)\end{array}$ & $\begin{array}{l}\text { Calculate the formation } \\
\text { energy of a point defect } \\
\text { in graphene material. }\end{array}$ & $\begin{array}{l}\text { Computational modeling } \\
\text { questions in assignment }\end{array}$ \\
\hline
\end{tabular}

\section{Results and Discussion Student Feedback}

Table II below shows the teaching evaluation results collected from 44 undergraduate students in response to the questions: Was the computational modeling class prepared well? Did the computational modeling modules foster learning? Did the assessment methods advance understanding of computational modeling techniques? And do you want to learn more and reuse the computational modeling tools in your other courses or research? The feedback is summarized as Agree, Neutral and Disagree.

"Was the computational modeling class prepared well?" The majority of students agreed with the good preparation for computational modeling class. It was the first time to integrate the computational modeling into undergraduate education in this way. Students' feedback suggested that the module development and lecture design fitted well to the undergraduate level.

The questions the students argued the most were related to the module implementation. "Did the computational modeling modules foster learning?" and "Did the assessment methods advance understanding of computational modeling techniques?" There were two key reasons causing 
students' negative feedback. They were limited lecture time and the complexity of computational modeling concepts and tools. As a prototype, 4 lectures (75 mins / lecture) were scheduled for computational modeling modules for each course. Except for study hours outside of the class, only 5 hours in the class were given to explain the concepts and carry out hands-on practice, posing a challenge to not only the students but also the instructor. In addition, the computational modeling concepts and tools are complex, because they are based on multiple scientific and engineering disciplines. Requiring the undergraduate students to fully understand them is an impossible mission. Therefore, finding the best balance between computational modeling theory and practice (e.g. how much and deep theory should be covered, and how much practice time should be scheduled) is needed.

Table II Summary of student feedback on computational modeling modules. In total, 44 undergraduate students returned the surveys.

\begin{tabular}{|l|c|c|c|}
\hline \multicolumn{1}{|c|}{ Evaluation Qs } & Agree & Neutral & Disagree \\
\hline $\begin{array}{l}\text { Was the computational } \\
\text { modeling class prepared } \\
\text { well? }\end{array}$ & 39 & 5 & 0 \\
\hline $\begin{array}{l}\text { Did the computational } \\
\text { modeling modules foster } \\
\text { learning? }\end{array}$ & 24 & 14 & 6 \\
\hline $\begin{array}{l}\text { Did the assessment } \\
\text { methods advance } \\
\text { understanding of } \\
\text { computational modeling } \\
\text { techniques? }\end{array}$ & 27 & 8 & 9 \\
\hline $\begin{array}{l}\text { Do you want to learn } \\
\text { more and re-use the } \\
\text { computational modeling } \\
\text { tools in your other } \\
\text { courses or research? }\end{array}$ & 25 & 6 & \\
\hline
\end{tabular}

In order to improve the computational modeling modules, the instructor will perform the strategies below for the future class:

- Create some brief must-remember notes to simply explain key computational modeling concepts.

These notes will be written in "very simple words" to explain the concepts so that the students can easily read and understand them, and they can also use the notes as a handbook to guide them to do simulation problems in the assignments and exams.

- Take two or three 5-min lecture videos for each class, and post them one week before the class.

The students can continue learning the theory and simulations outside of the class. 
- Modify the teaching strategies

In the class, the instructor will demonstrate a computational modeling tool first, followed by a lecture, and finally modeling practice. Using more real-world examples will help.

- Schedule more practice classes and help sessions

If possible, the instructor will schedule more practice classes and guide the students to learn from practice. Help sessions outside of the class will be helpful for Q\&A and any technical/computer problems.

Table II also shows that the module implementation significantly affects the student willingness to further study and apply the computational modeling techniques outside of the class. Enhancing the student awareness of importance of computational modeling and their interest of using the techniques can greatly broaden the participation and impact of the computational modeling field.

\section{Conclusion}

To meet national workforce need, we developed different computational modeling modules and taught the modules in two undergraduate materials science and engineering course, including Structure of Materials course and Thermodynamics course. Students studied the computational modeling theory outside of the class. In the class, the instructor focused on hands-on practice. The module s covered various materials structure and thermodynamic topics, such as atom and bonding simulations, point defect formation energy calculations and diffusion simulations, chemical reaction simulations, Gibbs free energy equilibrium calculations, and phase separation simulations. Student feedback was collected in consideration of the module document preparation and implementation. Majority of the students agreed that the module development and lecture design fitted well to the undergraduate level, but the module implementation needed to be further improved, such as increasing lecture time and finding the best balance between computational modeling theory and practice.

\section{References}

1. J. M. Wing, "Computational Thinking”, Communications of the ACM 49, 33-35 (2006).

2. V. Barr and C. Stephenson, "Bringing computational thinking to K-12: what is Involved and what is the role of the computer science education community", ACM Inroads 2, 48-54 (2011).

3. National Materials Advisory Board, Committee on Integrated Computational Materials Engineering: integrated computational materials engineering a transformational discipline for improved competitiveness and national security, National Academics Press, Washington, DC, 2008.

4. National Research Council, Integrated Computational Materials Engineering. Washington, DC: The National Academies Press (2008).

${ }^{5 .} \mathrm{K}$. Thornton and M. Asta, "Current status and outlook of computational materials science education in the US", Modeling Simul. Mater. Sci. Eng. 13, R53-R69 (2005).

6. J. M. Rickman and R. P. Vinci, “A Computational Materials Science Course for Undergraduate Majors”, JOM-e (Dec, 2003). 